\title{
ANÁLISE DE FALHA EM UMA LÂMINA DE FEIXE DE MOLAS ${ }^{1}$
}

\author{
Lucas Grilo Mendonça² \\ Marcelo Moussalle Macedo ${ }^{3}$ \\ Gabriel $\mathrm{Cogo}^{3}$ \\ Pedro Henrique Costa Pereira da Cunha ${ }^{4}$ \\ Marcio Levi Kramer de Macedo ${ }^{5}$ \\ Telmo Roberto Strohaecker ${ }^{6}$
}

\section{Resumo}

Os feixes de molas são componentes mecânicos automotivos constituídos basicamente de barras denominadas lâminas, fixadas por parafusos, e têm como característica atuar como elemento elástico e estrutural nas suspensões de eixo rígido, absorvendo os movimentos de baixa frequência e grande amplitude proporcionando conforto e estabilidade, além de manter o eixo posicionado corretamente em relação ao chassi do veículo. O objetivo do presente trabalho foi identificar a(s) causa(s) que levaram a lâmina à falha. Para isso, foram realizadas: análise química, fractografia, microscopia ótica e eletrônica de varredura e ensaios de microdureza. Os resultados dos ensaios realizados demonstraram que o tipo de mecanismo de falha ocorrido no componente foi o de fadiga, a partir de uma microtrinca que teve origem nos pontos de corrosão e deformação plástica na superfície da lâmina, provocados pelo desgaste da borracha protetora entre o feixe de molas e a estrutura do veículo.

Palavras-chave: Análise; Falha; Lâmina; Mola.

\begin{abstract}
The leaf springs are mechanical automotive components consisting basically by bars called slides fixed with screws, and that are characterized as an structural and elastic element in the rigid axle suspensions, absorbing the movements of low frequency and large amplitude and in that way providing comfort, stability and maintaining the axis positioned correctly in relation to the vehicle chassis. The aim of this study was identify the cause that lead the blade to failure. For this, some test were carried out, such as: chemical analysis, fractography analysis in optical microscopy and scanning electron microscopy and microhardness tests. Test results have shown that the component failure by fatigue, the failure starts in some points of corrosion and plastic deformation on the surface of the blade, caused by wear protective rubber between the beam springs and the vehicle structure.
\end{abstract}

FAILURE ANALYSIS OF LEAF SPRINGS

Key words: Analysis; Failure; Slides; Spring.

1 Contribuição técnica ao $68^{\circ}$ Congresso Anual da ABM - Internacional, 30 de julho a 2 de agosto de 2013, Belo Horizonte, MG, Brasil.

2 Graduando em Engenharia Metalúrgica. Bolsista de Iniciação Científica. Laboratório de Metalurgia Física - LAMEF, UFRGS, Porto Alegre, RS, Brasil.

Mestrando em Ciências dos Materiais. LAMEF, UFRGS, Porto Alegre, RS, Brasil.

Doutorando em Ciências dos Materiais. LAMEF, UFRGS, Porto Alegre, RS, Brasil.

Engenheiro Metalúrgico, Doutor. Coordenador do Grupo de Análise de Falhas. LAMEF, UFRGS, Porto Alegre, RS, Brasil.

6 Engenheiro Metalúrgico, Dr. Professor. Coordenador do LAMEF, UFRGS, Porto Alegre, RS, Brasil. 
$68^{\text {th }}$ abm international annual congress

\section{INTRODUÇÃO}

Os feixes de molas (Figura 1) são componentes mecânicos automotivos constituídos de barras denominadas lâminas, e são aplicados em automóveis, caminhões, ônibus e pick-ups. Cada uma das lâminas que constituem o feixe possui tamanhos diferentes, e são fixadas por suportes com parafusos, além de borrachas para diminuir o atrito entre os componentes.
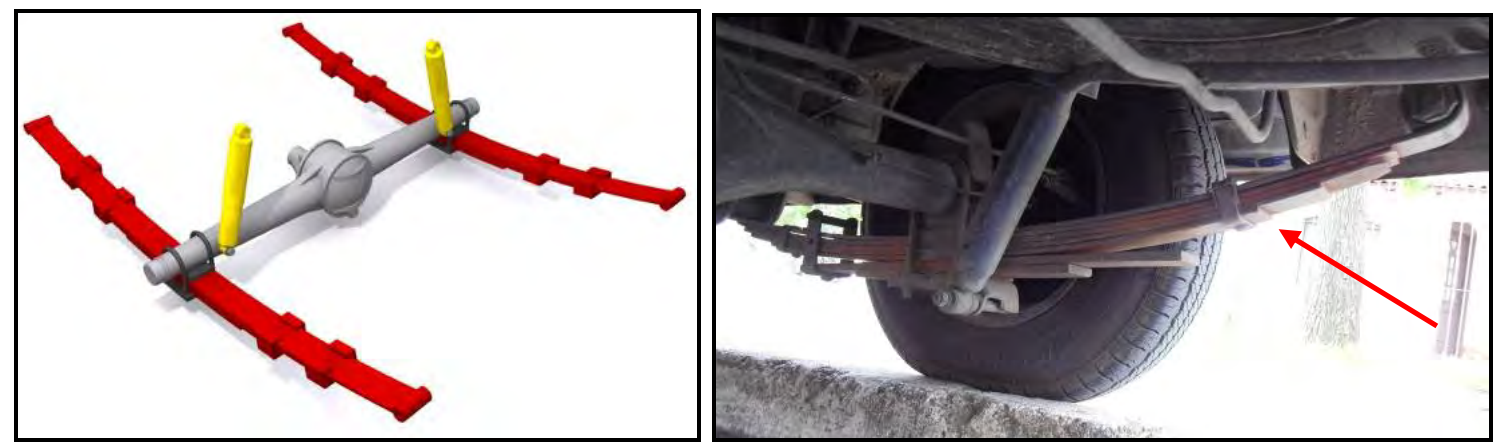

Figura 1. Desenho esquemático e ilustração do sistema de feixe de molas.

Este componente tem como característica atuar como elemento elástico e estrutural nas suspensões de eixo rígido, absorvendo os movimentos de baixa frequência e grande amplitude, proporcionando conforto e estabilidade.

Para que as lâminas do feixe de molas possuam uma vida útil longa são necessários alguns cuidados nos componentes do conjunto, como por exemplo: alinhamento, estado de conservação das borrachas e lubrificação de forma adequada. ${ }^{(1)}$

A metodologia de análise de falhas é uma ferramenta muito importante e fortemente empregada para identificar os motivos pelos quais a falha ocorreu e, dessa forma, evitar futuros problemas operacionais e acidentes. ${ }^{(2)}$

\section{MATERIAIS E MÉTODOS}

O objeto de estudo dessa análise de falha é a lâmina principal de um feixe de molas que falhou em serviço e está apresentada na Figura 2.

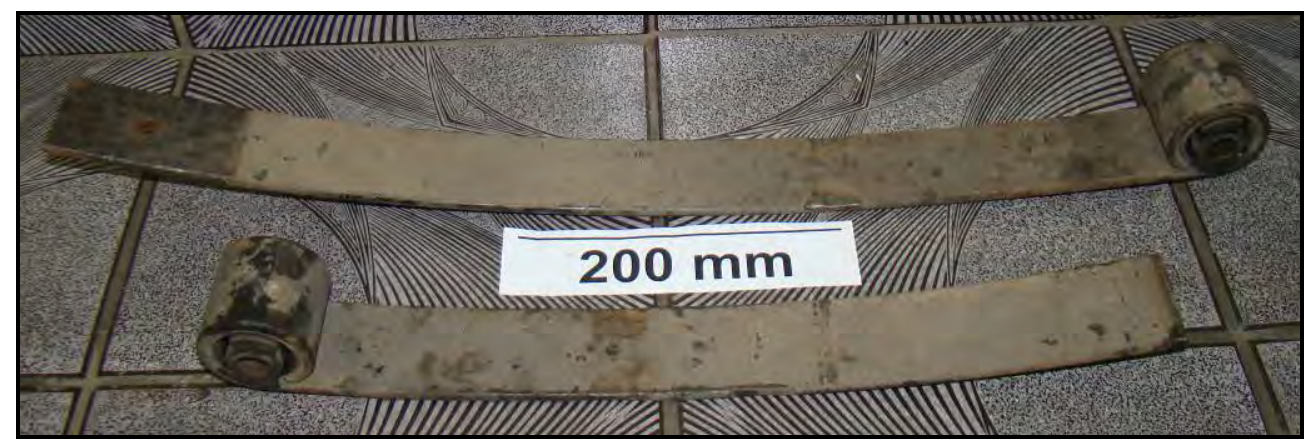

Figura 2. Componente recebido para a análise de falha.

A análise de falha do componente consistiu primeiramente na inspeção visual da região fraturada e identificação dos mecanismos de fratura através da visualização das superfícies em lupa de baixo aumento.

Além disso, foram realizados ensaios de dureza na escala Rockwell $C$ na lateral e na superfície da lâmina, e caracterização microestrutural. A microestrutura foi verificada via microscopia ótica, sendo as amostras retiradas nas proximidades do local onde 
ocorreu a falha. Uma solução com $2 \%$ de $\mathrm{HNO}_{3}$ diluído em álcool (Nital 2\%) foi o reagente utilizado para o ataque metalográfico das amostras. O ensaio de dureza foi realizado obtendo-se a média de cinco medidas. Os perfis de microdureza foram efetuados em um microdurômetro automatizado Instron-Tukon, na escala Vickers com carga de 300 gf. Foram realizadas medições de dureza em região próxima do início da falha.

\section{RESULTADOS}

Foi realizada documentação fotográfica com máquina digital das regiões deformadas e da superfície de fratura da lâmina, conforme mostram as imagens das Figuras 3 e 4. Na análise dos desgastes, a região que estava interligada ao suporte central do feixe de molas, separado pela borracha protetora apresentou alto grau de corrosão e deformação plástica, está também presente nas extremidades da lâmina.
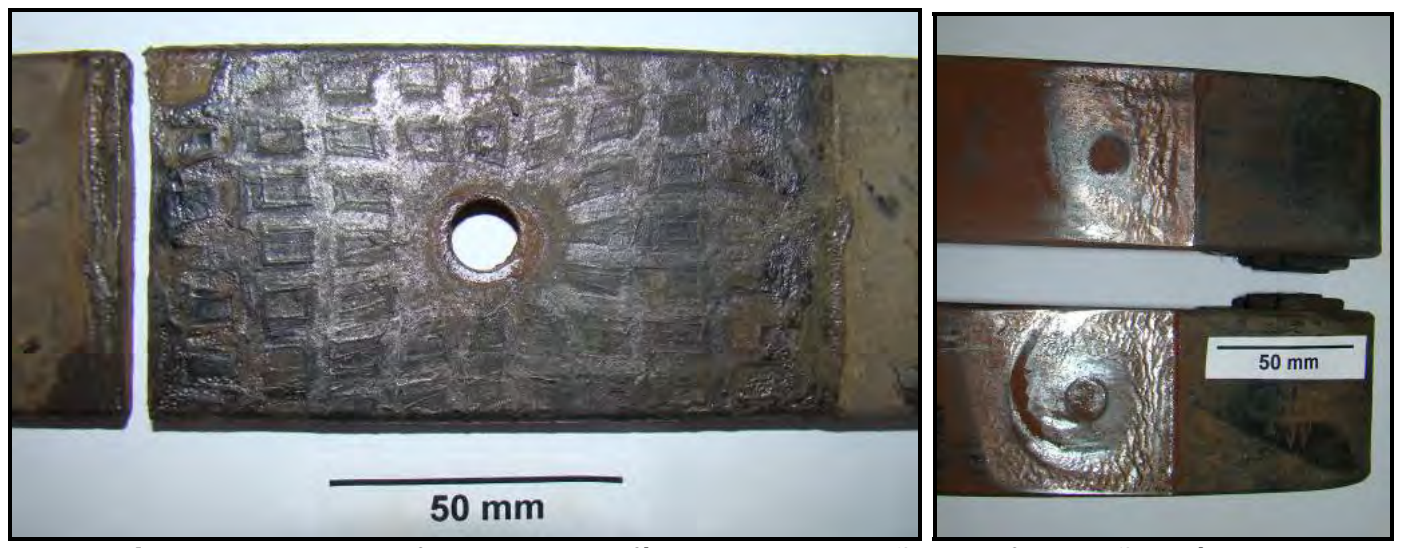

Figura 3. Macrografias das superfícies com corrosão e deformação plástica.

A falha ocorreu em um ponto sob a borracha protetora entre o feixe e o suporte central. A superfície de fratura é apresentada na Figura 4.

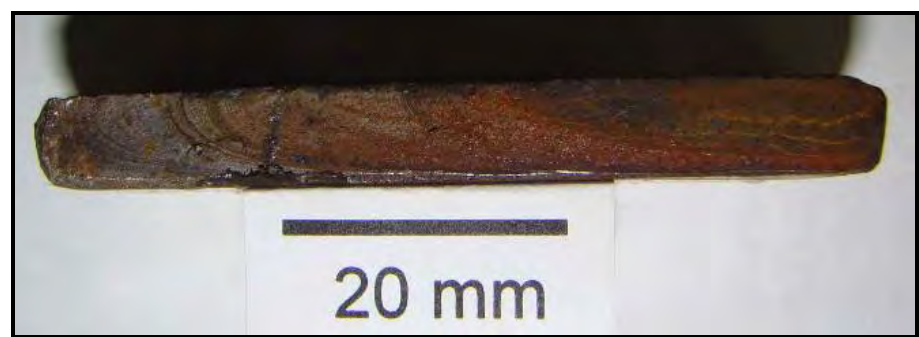

Figura 4. Macrografia da superfície de fratura.

A análise em microscopia eletrônica de varredura (MEV) consistiu em analisar a superfície da fratura. No entanto, mesmo após limpeza prévia em banho de acetona com agitação ultrassônica, além da utilização do reagente Clark $\left(20 \mathrm{~g} \mathrm{Sb}_{2} \mathrm{O}_{3}+50 \mathrm{~g}\right.$ $\mathrm{SnCl}_{2}+1 \mathrm{~L} \mathrm{HCl}$ ), não foi possível retirar completamente a oxidação superficial, o que impossibilitou a visualização de qualquer micromecanismo de fratura (Figura 5). 
$68^{\text {th }} \mathrm{abm}$ international annual congress

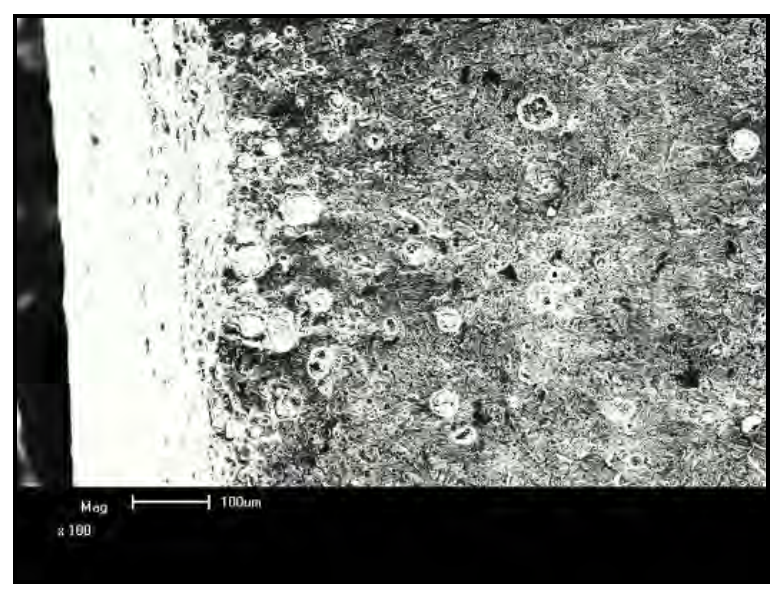

Figura 5. Imagem obtida via MEV, evidenciando alto grau de oxidação superficial.

A análise da superfície de fratura em lupa de baixo aumento evidenciou a presença de marcas de praia, característica das fraturas por fadiga (Figura 6).
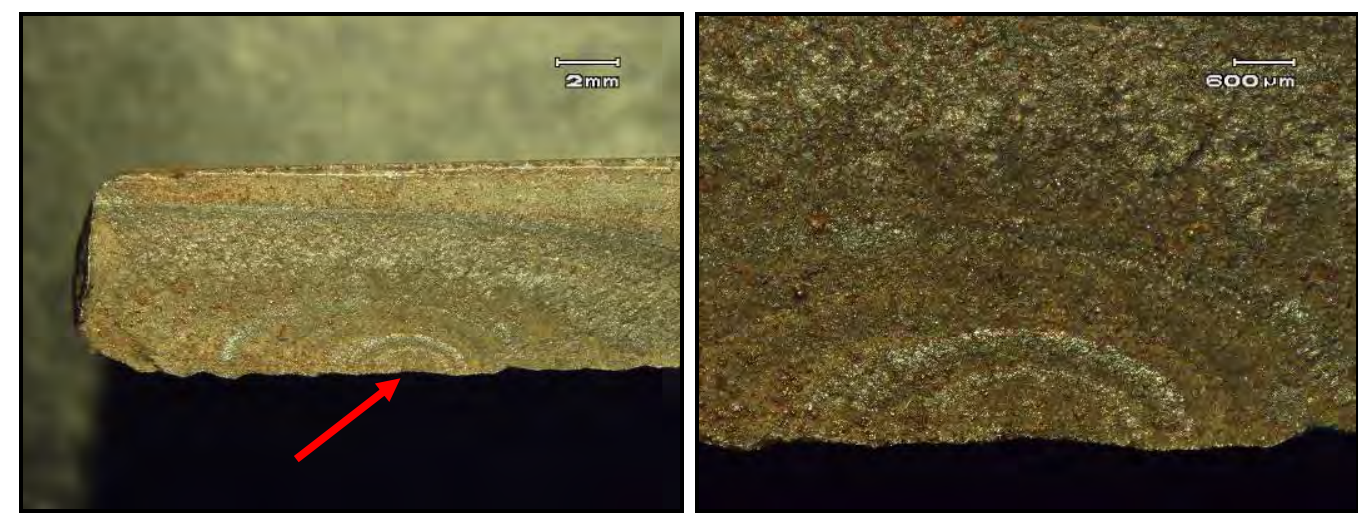

Figura 6. Presença de marcas de praia, com a seta indicando a região de início da falha.

Para análise da microestrutura o componente foi seccionado (Figura 7). A linha pontilhada na imagem da esquerda indica o plano de corte com a seta indicando o sentido de observação. A elipse na figura da direita indica a região de início, visualizada na amostra já preparada para observação. A amostra foi preparada para observação metalográfica e atacada com o reagente químico Nital $2 \%$. As análises foram realizadas em um microscópio ótico (MO) marca Olympus modelo BX 51M com as micrografias obtidas através de câmara digital acoplada ao microscópio.
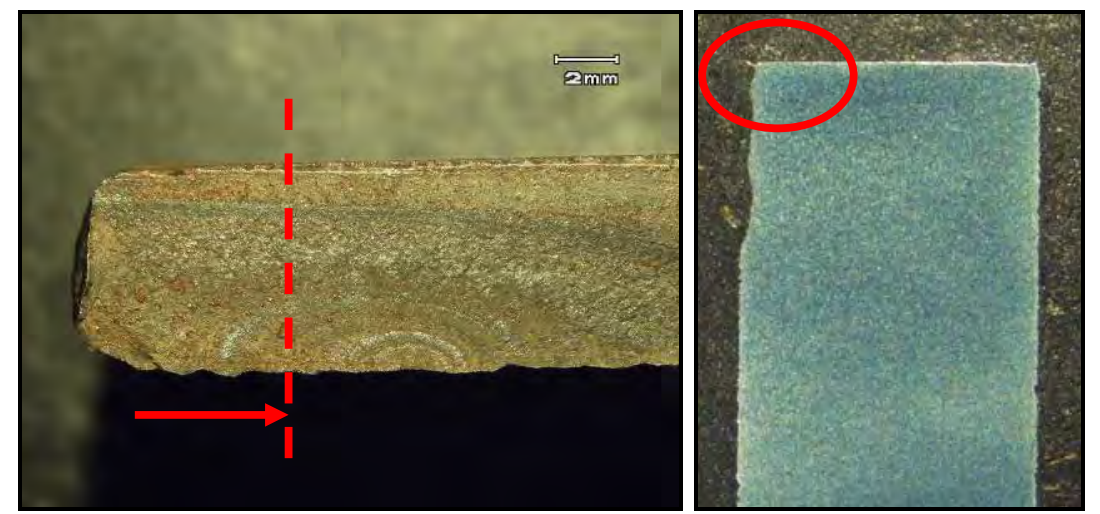

Figura 7. Imagens destacando a região do corte realizado no corpo de prova para metalografia, o sentido e região da análise. 
O componente apresentou microestrutura composta predominantemente por martensita revenida na região junto à superfície de fratura, conforme mostram as micrografias em diferentes aumentos da Figura 8.
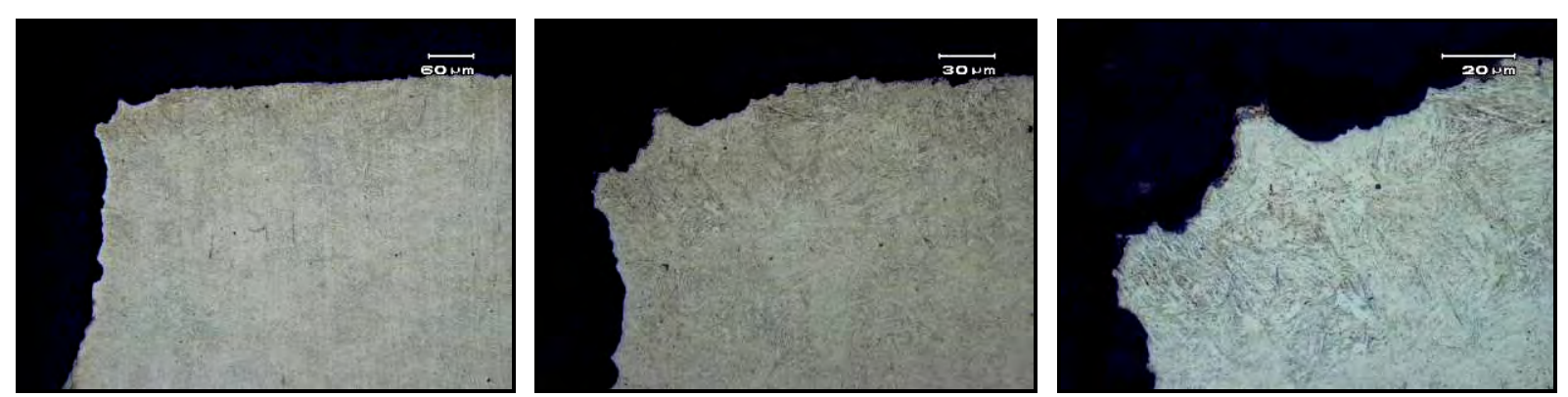

Figura 8. Microestrutura da lâmina junto à superfície de fratura composta de martensita revenida e pequena porção de ferrita.

Na região do núcleo da lâmina, além da microestrutura composta por martensita revenida, é possível observar também pequena quantidade de ferrita (Figura 9), com micrografias em diferentes aumentos.
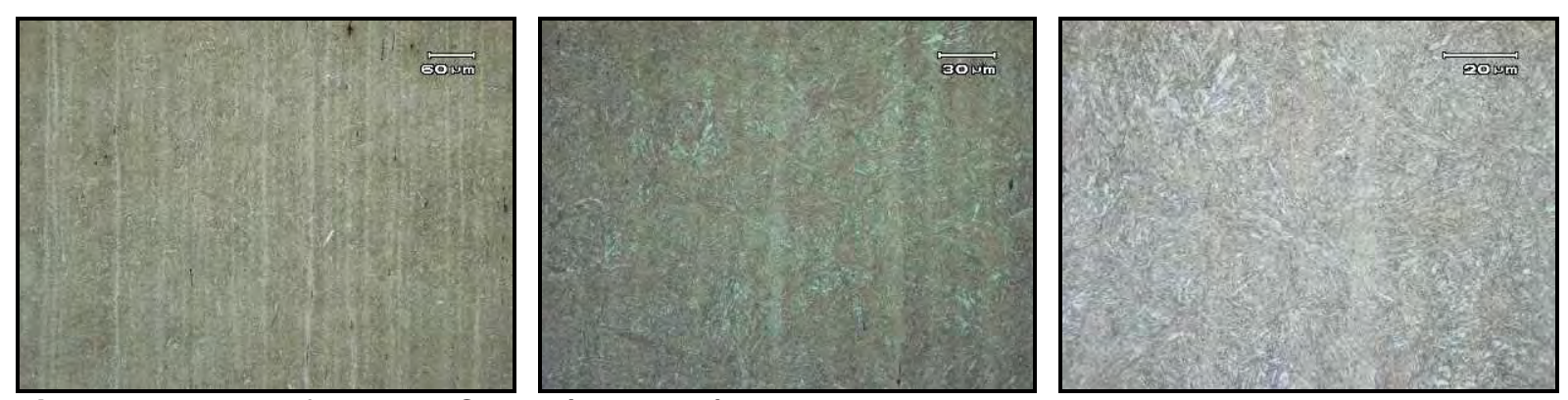

Figura 9. Micrografias em MO do núcleo da lâmina. Microestrutura composta de martensita revenida e pequena quantidade de ferrita.

Nas regiões próximas à superfície do componente observa-se a mesma microestrutura do núcleo da lâmina, além de pontos de corrosão, indicados pelas setas na Figura 10. Tal corrosão pôde ser observada na primeira imagem da documentação fotográfica da Figura 3.
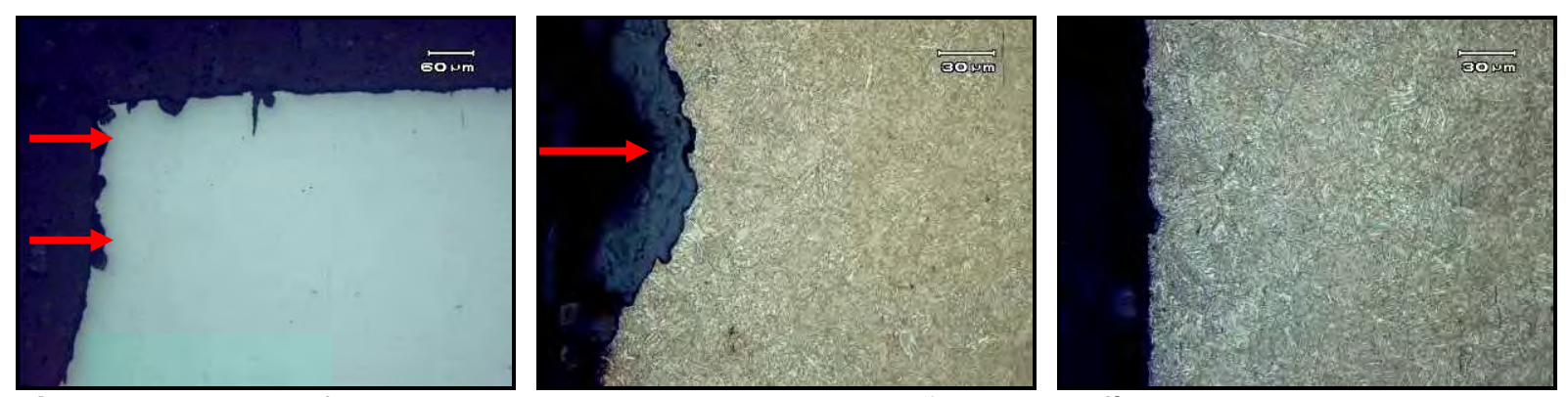

Figura 10. Micrografias evidenciando a presença de corrosão na superfície do componente, indicada pela seta.

Na região do núcleo da lâmina foi realizada análise de tamanho de grão, utilizandose ataque químico com reagente específico para contorno de grão em aço baixo carbono (500 mL H${ }_{2} \mathrm{O}+50 \mathrm{~g}$ ácido Pícrico $+1 \mathrm{~mL} \mathrm{HCl}+$ tensoativo). O tamanho de grão medido para a austenita prévia foi de 9 ASTM. $^{\left({ }^{(3)}\right.}$ As imagens podem ser observadas na Figura 11. 

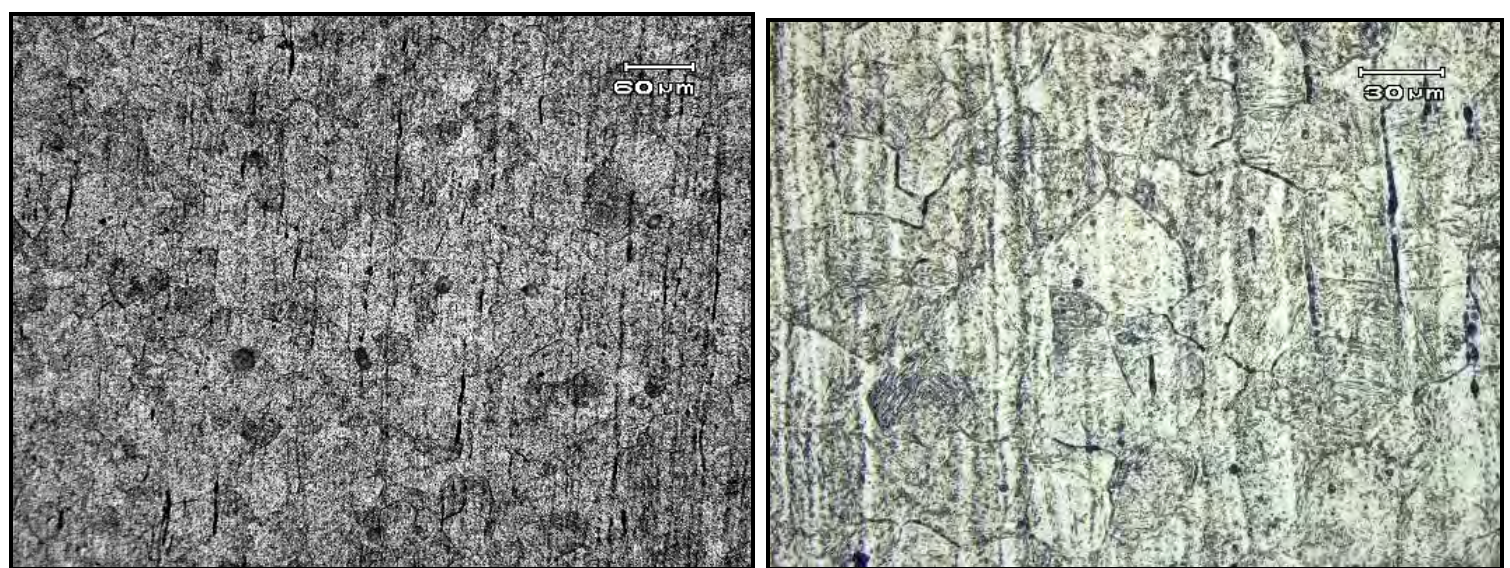

Figura 11. Micrografias em MO do núcleo da lâmina evidenciando o tamanho de grão do material.

Os ensaios de dureza foram realizados na superfície e lateral da lâmina em um durômetro AWPMA na escala Rockwell C (HRC). A Tabela 1 apresenta os resultados obtidos.

Tabela 1. Resultados dos ensaios de dureza Rockwell C realizados no componente

\begin{tabular}{|c|c|c|c|c|c|c|c|}
\hline Ensaio & Localização & $\mathbf{1}$ & $\mathbf{2}$ & $\mathbf{3}$ & $\mathbf{4}$ & $\mathbf{5}$ & Média \\
\hline Dureza (HRC) & Superfície & 45,5 & 46,1 & 45,1 & 44,1 & 45,5 & 45,3 \\
\hline Dureza (HRC) & Lateral & 45,0 & 45,8 & 45,5 & 46,5 & 46,0 & 45,8 \\
\hline
\end{tabular}

$\mathrm{Na}$ amostra próxima à região de início da falha foram realizados perfis de microdureza na escala Vickers em duas regiões distintas (Figura 12): um perfil paralelo à superfície de fratura (Perfil Vertical) e outro paralelo à superfície da lâmina (ortogonal à superfície de fratura - Perfil Horizontal).

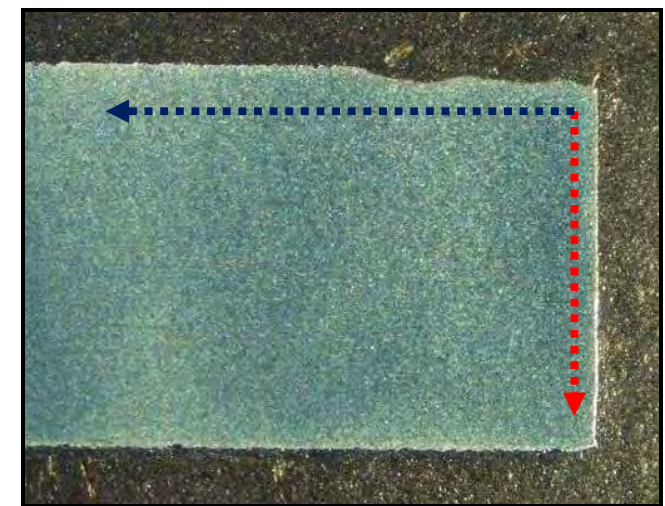

Figura 12. Amostra embutida da região próxima ao início da falha e indicação da orientação dos perfis de microdureza realizados.

As medições foram realizadas partindo da região de início da falha, localizada no canto superior direito da Figura 12. Os resultados foram plotados no gráfico apresentado na Figura 13. 


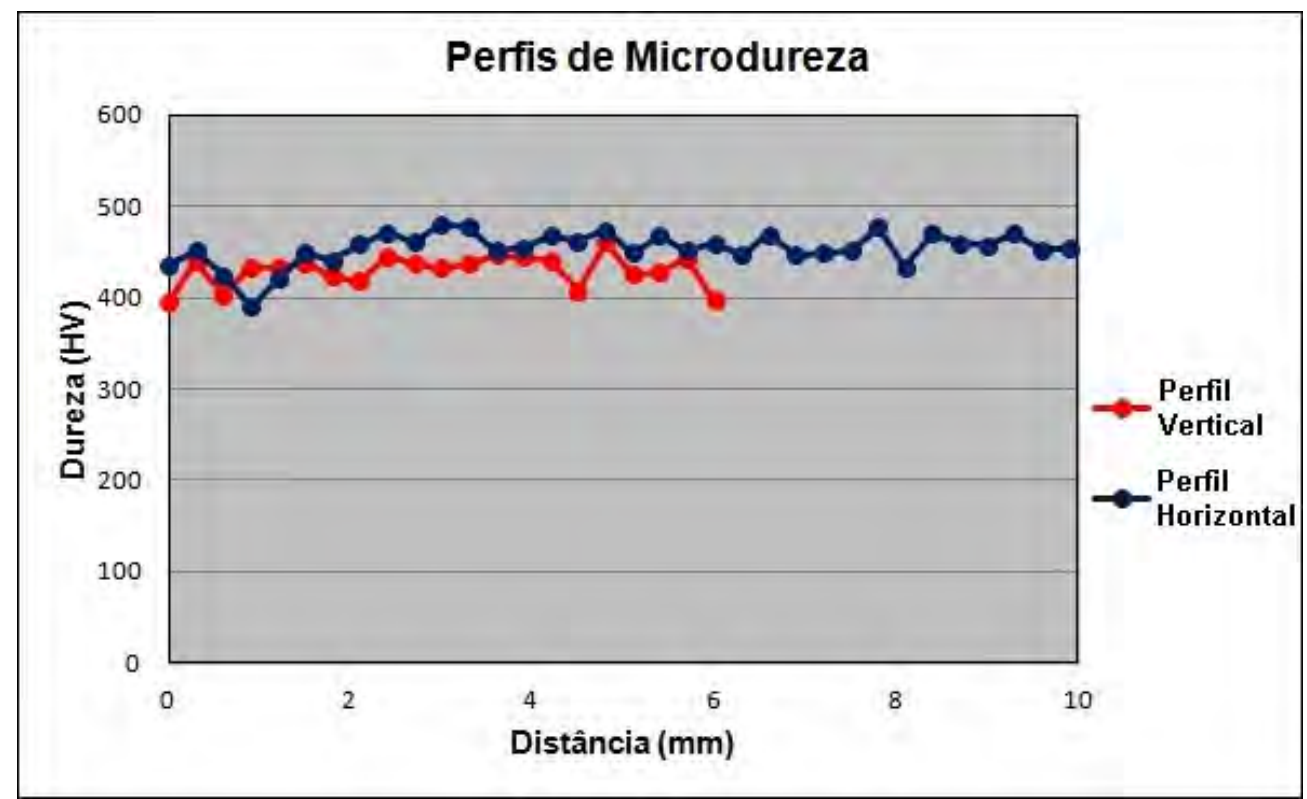

Figura 13. Gráfico ilustrando a variação de dureza da superfície de fratura e superfície da lâmina.

A análise química foi realizada via Espectrometria de Emissão Ótica, em um equipamento da marca Spectro. A composição química obtida é similar a de um aço SAE 5160, ${ }^{(4)}$ porém o teor de Manganês encontrou-se levemente abaixo do especificado. Os resultados são apresentados na Tabela 2.

Tabela 2. Resultado da análise química (\% em massa)

\begin{tabular}{|c|c|c|c|c|c|c|}
\hline & $\mathbf{C}$ & $\mathbf{M n}$ & $\mathbf{P}$ & $\mathbf{S}$ & $\mathbf{S i}$ & $\mathbf{C r}$ \\
\hline Amostra & 0,551 & 0,627 & 0,01 & 0,008 & 0,205 & 0,705 \\
\hline Aç̧o SAE & $0,56-$ & $0,75-$ & 0,030 & 0,040 & $0,15-$ & $0,70-$ \\
$\mathbf{5 1 6 0}$ & 0,64 & 1,00 & máx. & máx. & 0,35 & 0,90 \\
\hline
\end{tabular}

\section{DISCUSSÃO}

Através da análise macrográfica e visual da área próxima à falha se observaram deformação plástica e alto grau de corrosão na região entre o feixe de molas e o suporte central. Tal Esta corrosão também foi evidenciada via microscopia ótica, salientando-se a presença de pontos de corrosão (pites), aspecto significativamente prejudicial para o comportamento em fadiga do componente. $\mathrm{Na}$ análise da superfície de fratura em lupa de baixo aumento pôde ser observada a presença de marcas de praia, características das fraturas por fadiga. ${ }^{(5)} \mathrm{Na}$ análise através de Microscopia Eletrônica de Varredura não foi possível visualizar micromecanismos de fratura devido ao grau de corrosão na superfície.

O material apresentou microestrutura predominantemente composta por martensita revenida, com pequena quantidade de ferrita nas regiões mais próximas ao núcleo do componente. O tamanho de grão verificado, 9 ASTM, é adequado para a microestrutura presente. ${ }^{(6)}$ Não foi observada alteração na microestrutura nas vizinhanças do ponto de início.

Os ensaios de dureza apresentaram valores dentro do especificado para o tipo de material aplicado neste componente. ${ }^{(7)}$

A análise química apresentou teor de Manganês levemente fora do especificado para um aço SAE 5160, porém tal resultado não é significativamente deletério para a propriedade mecânica do material. ${ }^{(4)}$ 


\section{CONCLUSÃO}

Pelas análises realizadas podem-se ter algumas interpretações a respeito da falha da lâmina. Observando macroscopicamente o componente, notou-se a presença de alto grau de oxidação e deformação plástica na região próxima à falha. Portanto, entendeu-se que a falta de manutenção, evidenciada pelo alto desgaste e oxidação do material foi o fator preponderante da falha, a qual ocorreu por fadiga, com ponto de início em um ponto de corrosão (pite) atuando como concentrador de tensões.

\section{Agradecimentos}

Os autores agradecem ao CNPQ/Capes pelo incentivo à pesquisa.

\section{REFERÊNCIAS}

1 TKB Molas Hoesch. Feixes de Molas. 2011. Disponível em: <http://www.hoesch.com.br/indez.php/produtos-feixes/feixes-de-molas>. Acesso em: 12 set. 2012.

2 CASSOU, C. A. Metodologia de Análise de Falhas. Dissertação de mestrado. Porto Alegre, 1999.

3 ASTM E 112 - 10 - Standard Test Methods for Determining Average Grain Size, 01.11.2010.

4 SOUZA, S. A. Composição Química dos Aços. São Paulo, 1a edição, 1989.

5 Metals Handbook. Fractography and Atlas of Fractographs - ASM American Society for Metals. V. 9, $8^{a}$ edição, 1974.

6 COLPAERT, H. Metalografia dos Produtos Siderúrgicos Comuns. São Paulo, $4^{a}$ edição, 2008.

7 Metals Handbook. Failure Analysis and Prevention - ASM American Society for Metals. V. 11, $9^{\circ}$ edição, 1988. 